University of Wollongong

Research Online

Faculty of Engineering - Papers (Archive)

Faculty of Engineering and Information

Sciences

$1-1-2009$

\title{
Cyclic deformation of advanced high-strength steels: Mechanical behavior and microstructural analysis
}

Timothy B. Hilditch

Deakin University

Ilana B. Timokhina

Deakin University, llana.Timokhina@eng.monash.edu.au

Leigh T. Robertson

Deakin University

E V. Pereloma

University of Wollongong, elenap@uow.edu.au

Peter D. Hodgson

Deakin University

Follow this and additional works at: https://ro.uow.edu.au/engpapers

Part of the Engineering Commons

https://ro.uow.edu.au/engpapers/2646

\section{Recommended Citation}

Hilditch, Timothy B.; Timokhina, llana B.; Robertson, Leigh T.; Pereloma, E V.; and Hodgson, Peter D.: Cyclic deformation of advanced high-strength steels: Mechanical behavior and microstructural analysis 2009, 342-353.

https://ro.uow.edu.au/engpapers/2646

Research Online is the open access institutional repository for the University of Wollongong. For further information contact the UOW Library: research-pubs@uow.edu.au 


\title{
Cyclic Deformation of Advanced High-Strength Steels: Mechanical Behavior and Microstructural Analysis
}

\author{
TIMOTHY B. HILDITCH, ILANA B. TIMOKHINA, LEIGH T. ROBERTSON, \\ ELENA V. PERELOMA, and PETER D. HODGSON
}

\begin{abstract}
The fatigue properties of multiphase steels are an important consideration in the automotive industry. The different microstructural phases present in these steels can influence the strain life and cyclic stabilized strength of the material due to the way in which these phases accommodate the applied cyclic strain. Fully reversed strain-controlled low-cycle fatigue tests have been used to determine the mechanical fatigue performance of a dual-phase (DP) 590 and transformationinduced plasticity (TRIP) 780 steel, with transmission electron microscopy (TEM) used to examine the deformed microstructures. It is shown that the higher strain life and cyclic stabilized strength of the TRIP steel can be attributed to an increased yield strength. Despite the presence of significant levels of retained austenite in the TRIP steel, both steels exhibited similar cyclic softening behavior at a range of strain amplitudes due to comparable ferrite volume fractions and yielding characteristics. Both steels formed low-energy dislocation structures in the ferrite during cyclic straining.
\end{abstract}

DOI: $10.1007 / \mathrm{s} 11661-008-9732-\mathrm{x}$

(C) The Minerals, Metals \& Materials Society and ASM International 2008

\section{INTRODUCTION}

THE increased use of advanced high-strength steels (AHSS) in the automotive industry is based on the need for weight savings in vehicles while maintaining or improving safety. The AHSS are multiphase steels that provide an improved strength and ductility combination over conventional high-strength steels. To fully realize their potential in automotive applications, it is necessary to understand the properties of particular interest to the automotive industry including fatigue resistance for improved component life, crush resistance for energy absorption in vehicle damage, and a high level of formability for manufacturability. In this respect, dual-phase (DP) steels have demonstrated a good compromise between strength and ductility. ${ }^{[1,2]}$ The DP steels exhibit a continuous yielding behavior, low yield point, and a high strain-hardening coefficient. ${ }^{[3,4]}$ This has been attributed to an increase in the workhardening parameters through the formation of mobile dislocations due to the martensite formation during processing, and martensite twinning during forming. ${ }^{[5]}$ Transformation-induced plasticity (TRIP) steels are another AHSS that have a unique strength ductility relationship due to the presence of stable retained austenite in the microstructure. The austenite is

TIMOTHY B. HILDITCH and ILANA B. TIMOKHINA, Research Academics, LEIGH T. ROBERTSON, Postdoctoral Student, and PETER D. HODGSON, Professor, are with Centre for Material and Fibre Innovation, Deakin University, Waurn Ponds, VIC, Australia, 3217. Contact e-mail: tim.hilditch@deakin.edu.au ELENA V. PERELOMA, Professor, is with School of Mechanical, Materials and Mechatronic Engineering, University of Wollongong, NSW, Australia, 2522.

Manuscript submitted May 11, 2008.

Article published online January 6, 2009 transformed to martensite in response to an applied load, ${ }^{[6,7]}$ resulting in an increase of both the tensile strength and ductility. The macroscopic plastic strain accompanying the austenite to martensite phase transformation under the stress is defined as transformation plasticity. The strain can arise from transformation shape change or plastic accommodation process, which occur around the martensite islands as they form. ${ }^{[8]}$

The fatigue performance of a vehicle is an important design and material selection consideration due to the repeated loads/strains that are experienced during normal use. While the vehicle is designed so that the stresses in a component are below the yield stress of the material, there are regions of stress concentration in the body structure that can generate small plastic strains. The presence of small inelastic strains, or microplasticity, in materials at stresses below the yield point may also make an important contribution to the fatigue properties. This makes it important to understand the effects of low-cycle fatigue (LCF) on the performance of automotive materials.

Fatigue results in the alteration of the internal structure of the material; thus, the distribution of the strain within the microstructure should have an important role in the cyclic response. This strain distribution can be especially important in multiphase steels where there may be strain partioning between the phases. ${ }^{[9]}$ Research examining the fatigue properties of several steel grades of similar strength have shown endurance limits increasing in the order of high-strength low-alloy (HSLA), DP, and TRIP. ${ }^{[10,11]}$ These results indicate that while the fatigue performance of steel is often linked to monotonic tensile strength, the microstructure may have some effect on the endurance limit. Research using strain-controlled fatigue has also shown the importance of the microstructure in different steels on the cyclic stress response, specifically, 
whether the material will soften or harden with repeated cyclic plastic. ${ }^{[12-16]}$ Previous studies have shown both cyclic softening and hardening for ferrite-based steels (depending on strain amplitude) ${ }^{[14]}$ cyclic hardening for ferrite-martensite based steels, ${ }^{[1,13]}$ and cyclic softening for austenite-based stainless steels. ${ }^{[16]}$ These differences suggest that for more complex microstructures containing multiple phases, such as TRIP steels, the cyclic stress response will depend on which phases are accommodating the strain.

It has been reported ${ }^{[17,18]}$ that the monotonic deformation of TRIP steels is controlled by two processes: (1) long-range internal stress resulting from a difference of plastic strain between the ferrite matrix and the second phase, and (2) strain-induced transformation of the retained austenite to martensite resulting in both increase in the martensite content and relaxation of the long-range internal stress. For TRIP steels, the main parameters that can affect the monotonic deformation in this respect are retained austenite and its carbon content, morphology, and distribution. ${ }^{[19]}$ The cyclic deformation of TRIP steels will be controlled by the accommodation of the small repeated plastic strains by the different phases within the microstructure. It is of interest to understand whether the role of the retained austenite in a TRIP steel in the control of the cyclic properties is as important as for the monotonic properties. The aim of this work is to understand how strain is accommodated in multiphase steels by examining the dislocation substructure generated during cyclic straining for a dual-phase steel, TRIP steel containing a significant amount of retained austenite, and the effect of these microscopic deformation structures on the macroscopic fatigue properties.

\section{EXPERIMENTAL}

\section{A. Materials}

The compositions of the commercially-produced uncoated DP 590 steel and TRIP 780 sheet steel are shown in Table I. Both steels had a nominal thickness of $2 \mathrm{~mm}$. True stress-strain properties were determined using tensile tests conducted in accordance with AS 1391-1991 on a $100 \mathrm{kN}$ screw-driven load frame at a constant crosshead velocity of $1.5 \mathrm{~mm} / \mathrm{min}$. Specimens had a nominal gage length of $25 \mathrm{~mm}$ and width of $6 \mathrm{~mm}$, and were tested in the longitudinal direction using a $25-\mathrm{mm}$ gage length clip-on extensometer to measure strain.

\section{B. Fatigue Testing}

Fully reversed strain amplitude $(R=-1)$ fatigue tests were performed in accordance with ASTM E606-92

Table I. Chemical Composition of Steels (Weight Percent)

\begin{tabular}{lcccccc}
\hline Steel & $\mathrm{C}$ & $\mathrm{Si}$ & $\mathrm{Mn}$ & $\mathrm{Al}$ & $\mathrm{Cu}$ & $\mathrm{Cr}$ \\
\hline TRIP & 0.12 & 1.77 & 1.39 & 0.031 & 0.005 & 0.02 \\
$\mathrm{DP}$ & 0.036 & 1.065 & 1.08 & 0.018 & 0.004 & 0.083 \\
\hline
\end{tabular}

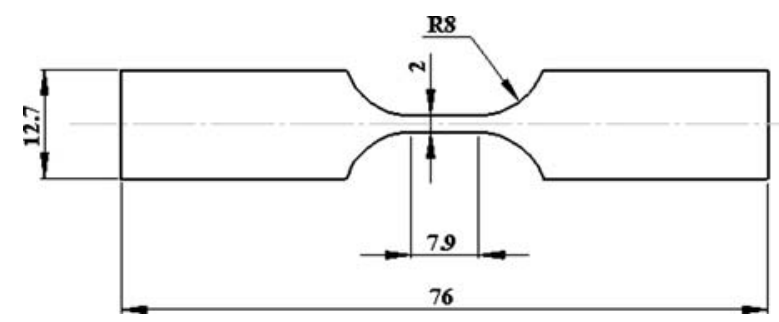

Fig. 1-Schematic of fatigue specimen geometry (dimensions in millimeters).

on a $25 \mathrm{kN}$ servohydraulic load frame. Specimens had a 2-mm width and 7.9-mm parallel length (Figure 1). Strain amplitudes in the range from 0.002 to 0.007 were applied in strain control mode using a 5 -mm gage length clip-on extensometer at a constant strain rate of $0.02 \mathrm{~s}^{-1}$. To prevent buckling under large compressive strains, anti-buckling guides were used. Epoxy was placed under the extensometer edges to prevent slippage or crack initiation at these points. Failure was determined as a load drop of 10 pct from that of the stabilized hysteresis loop.

\section{X-Ray Analysis}

$\mathrm{X}$-ray diffraction analysis was carried out using a PHILIPS* PW $1130(40 \mathrm{kV}, 25 \mathrm{~mA})$ diffractometer

*PHILIPS is a trademark of Philips Electronic Instruments Corp., Mahwah, NJ.

equipped with a monochromator and $\mathrm{Cu} K_{\alpha}$ radiation to determine the amount of martensite and retained austenite in the microstructure. Spectra were taken in the range of $2 \theta$ from 30 to 90 deg with a 0.5 -deg step size and the integrated intensities of the $(200)_{\alpha},(211)_{\gamma},(200)_{\gamma}$, and $(220)$, peaks were used in the direct comparison method. ${ }^{[20]}$ The X-ray diffraction data were also used to calculate the carbon concentration in the retained austenite lattice using the following equation: ${ }^{[21]}$

$$
\begin{aligned}
\alpha_{\gamma}= & (0.363067+0.0783 /(1+0.2151(100 / \text { wt pct } \mathrm{C}-1))) \\
& \times(1+(24.92-1 /(1+0.2151(100 / \text { wt pct } \mathrm{C}-1))) \\
& \times 10^{-6}(T-727)
\end{aligned}
$$

\section{Transmission Electron Microscopy}

The samples for transmission electron microscopy (TEM) were sectioned close to the fracture surface in two directions; perpendicular to the deformation direction to examine the deformed microstructure and perpendicular to the deformation direction to study the morphology of the shear bands. The microstructure was characterized using a PHILIPS CM 20, operated at $200 \mathrm{kV}$. Thin foils for TEM were prepared by twin-jet electropolishing using a solution of 5 pct perchloric acid in methanol at $-20{ }^{\circ} \mathrm{C}$ and an operating voltage of $30 \mathrm{~V}$. Observations were made in both the bright- and 
dark-field imaging modes and selected area electron diffraction (SAED) patterns were recorded from areas of interest using an aperture of $1.1 \mu \mathrm{m}$ nominal diameter. The misorientation between subgrains was measured by the microbeam diffraction (MBED) technique using 30 data points. The MBED patterns were obtained using a nominal probe diameter of $15 \mathrm{~nm}$. Microband and cell thicknesses were measured by the linear intercept method on 4 to 5 TEM negatives at a magnification of 15,000 times. The dislocation density was calculated by measuring the total dislocation line length in a unit volume of crystal giving a parameter in terms of length $(\mathrm{m}) / \mathrm{m}^{3}$, with the dislocation density $(\Lambda)$ given by ${ }^{[22]}$

$$
\Lambda=2 N_{L} / L t
$$

where $N_{L}$ is the number of intersections with dislocations, $L$ is the length of random lines, and $t$ is the foil thickness. For this purpose, at least 20 intercepts were recorded at 88,000 times magnification. The foil thickness was determined from intensity oscillations in the two-beam convergent electron diffraction patterns. ${ }^{[23]}$ The electron beam was focused onto an area of the matrix that is free from defects, where the thickness of the foil was to be determined. The diffracted spot in the pattern contains fringes of intensity minima and the deviation of $i$ th intensity minimum from the exact Bragg condition is

$$
s_{i}=\frac{\Delta \theta_{i} \lambda}{2 \theta_{B} d_{h k i l}^{2}}
$$

where $\Delta \theta$ is the deviation of the $i$ intensity minimum from $2 \theta_{B}, \lambda$ is the electron wavelength, $d_{h k i l}$ is the interplanar spacing of the operating reflection, $\theta_{B}$ is the Bragg angle for the diffracting plane $d_{h k i l}$, and $2 \theta_{B}$ corresponds to the distance between the transmitted and diffracted spots. The foil thickness can be determined from the equation

$$
\frac{1}{t^{2}}=\frac{s_{i}^{2}}{n_{k}^{2}}+\frac{1}{\xi_{g}^{2} n_{k}^{2}}
$$

where $\xi_{g}$ is the extension distance and $t$ is the foil thickness.

\section{RESULTS AND DISCUSSION}

\section{A. Microstructural and Tensile Characterization of As-Received Multiphase Steels}

The microstructure of the DP steel consisted of $\sim 75 \pm 5$ pct polygonal ferrite and $\sim 15 \pm 4$ pct of martensite (Figure 2(a)). The TEM revealed the presence of a small amount of bainite and retained austenite in the microstructure. The microstructure of the DP steel was also characterized by a large number of fine and coarse $\mathrm{Fe}_{3} \mathrm{C}$ carbides. The ferrite grain size was $\sim 9 \pm 1.9 \mu \mathrm{m}$ and the average dislocation density of polygonal ferrite interior regions away from the interface regions was $0.96 \pm 0.04 \times 10^{14} \mathrm{~m}^{-2}$ as shown in Table II. However, a local increase in the dislocation density $(5 \pm 0.8 \times$ $10^{14} \mathrm{~m}^{-2}$ ) was observed in the polygonal ferrite areas

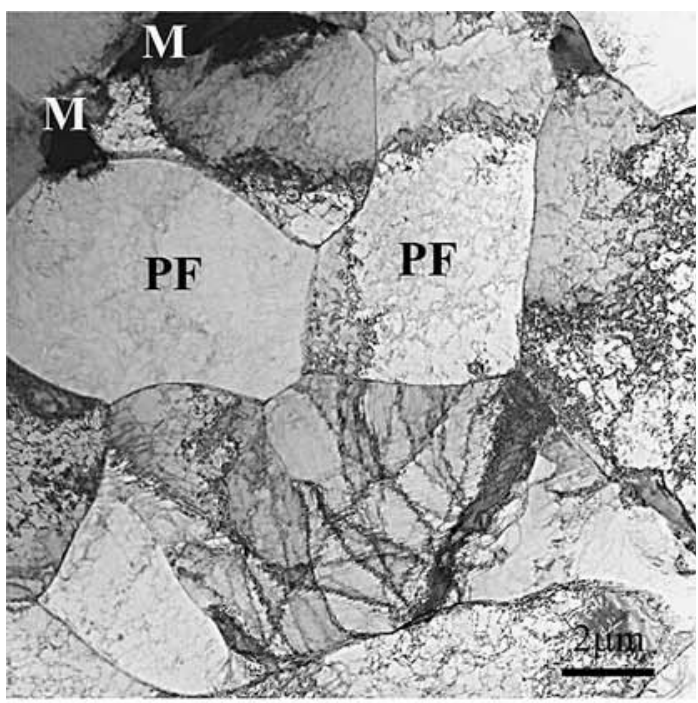

(a)

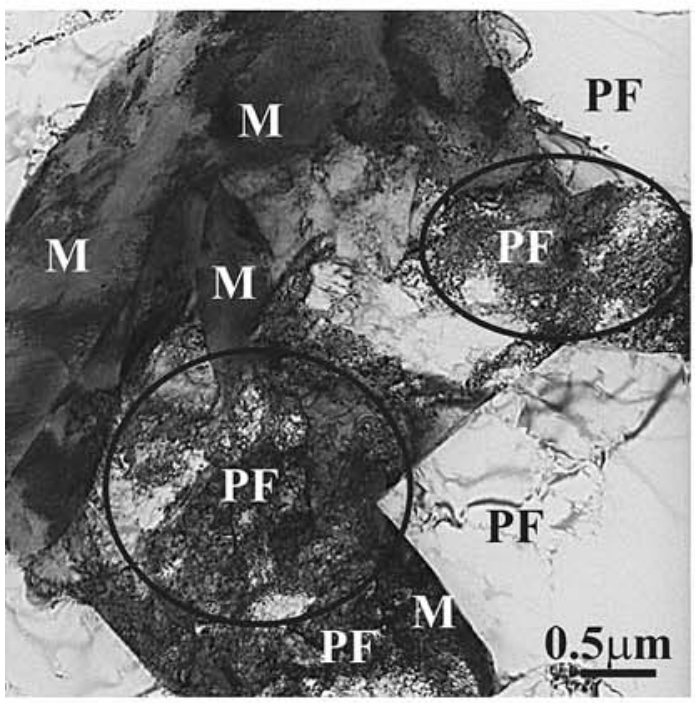

(b)

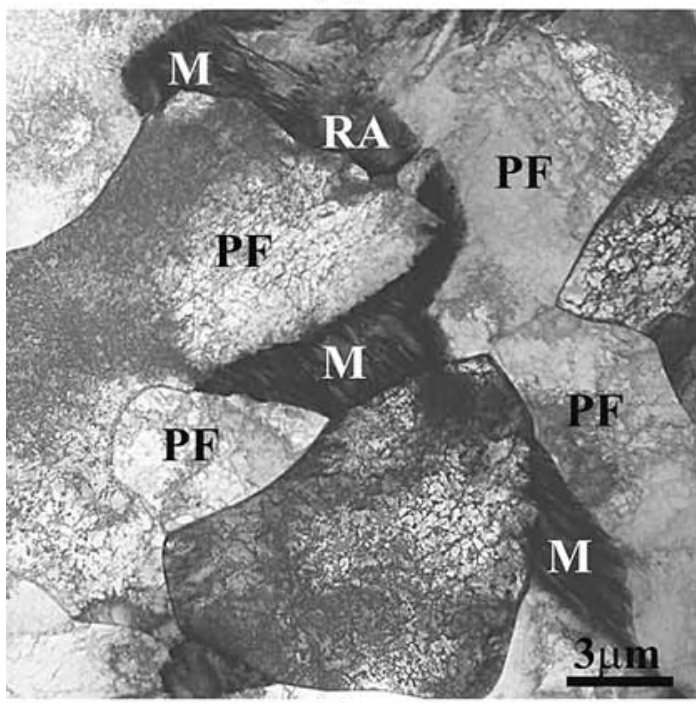

(c)

Fig. 2-TEM micrographs of (a) microstructure of DP steel, $(b)$ dislocations at the ferrite/martensite interface, and $(c)$ microstructure of TRIP steel. 
Table II. Dislocation Density in the As-Received Materials

\begin{tabular}{|c|c|c|c|}
\hline \multirow[b]{2}{*}{ Microstructural Feature } & \multicolumn{2}{|c|}{ DP } & \multirow{2}{*}{$\begin{array}{c}\text { TRIP } \\
\text { Average }\end{array}$} \\
\hline & Average & Local & \\
\hline $\begin{array}{l}\text { Dislocation } \\
\quad \text { density, } \times 10^{14} \mathrm{~m}^{-2}\end{array}$ & $0.96 \pm 0.04$ & $5 \pm 0.8$ & $1.75 \pm 0.09$ \\
\hline $\begin{array}{l}\text { Average distance between } \\
\text { dislocations, } \mathrm{nm}\end{array}$ & $309 \pm 28$ & $200 \pm 20$ & $189 \pm 20$ \\
\hline
\end{tabular}

Table III. Mechanical Tensile Properties of the As-Received Materials

\begin{tabular}{lccccc}
\hline Material & $\begin{array}{c}\text { 0.2 Pct } \\
\text { YS (MPa) }\end{array}$ & $\begin{array}{c}\text { UTS } \\
(\mathrm{MPa})\end{array}$ & $n$ & \multicolumn{1}{c}{$K$} & $\begin{array}{c}\text { Uniform } \\
\text { Elongation } \\
\text { (Pct) }\end{array}$ \\
\hline DP 590 & 500 & 770 & 0.15 & 975 & 19.4 \\
TRIP 780 & 590 & 1045 & 0.21 & 1310 & 28.5 \\
\hline
\end{tabular}

adjacent to the martensite regions (Figure 2(b)). This is believed to be due to the stress propagation of the martensite into the soft ferrite matrix associated with the volume increase when martensite forms from austenite during cooling.

The microstructure of the TRIP steel consisted of $\sim 70 \pm 3$ pct polygonal ferrite and $\sim 20 \pm 3$ pct retained austenite. The other main phases found in the microstructure were bainite and martensite (Figure 2(c)). The retained austenite had an average carbon content of $1.2 \pm 0.05 \mathrm{wt}$ pct, and appeared to be in the form of a martensite/retained austenite constituent between the bainitic ferrite or as islands between the polygonal ferrite grains. The polygonal ferrite grain size was $6.5 \pm 0.2 \mu \mathrm{m}$ with an average dislocation density of $1.75 \pm 0.09 \times 10^{14} \mathrm{~m}^{-2}$.

The true stress-strain tensile properties of both steels are summarized in Table III. The work-hardening exponent $n$ was calculated between 5 and 15 pct strain. Comparison of the true-stress strain plots of the two steels in Figure 3 shows that both materials had similar initial work-hardening rates. The DP steel had a yield stress higher than customarily observed for this type of steel; most likely the result of natural aging.

\section{B. Strain Life}

Figure 4 shows an increase in the number of reversalsto-failure with decreasing strain amplitude for both TRIP 780 and DP 590. The TRIP 780 had an increased strain life compared to the DP steel over the range of strain amplitudes tested. The trendline shows that the improved fatigue life for the TRIP steel was relatively constant for the entire range of strain examined.

\section{Cyclic Stress Response}

Figure 5 shows the peak tensile cyclic stress vs number of cycles for DP 590 at a range of strain amplitudes. At strain amplitudes 0.005 and below, the maximum stress was achieved on the initial strain cycle and

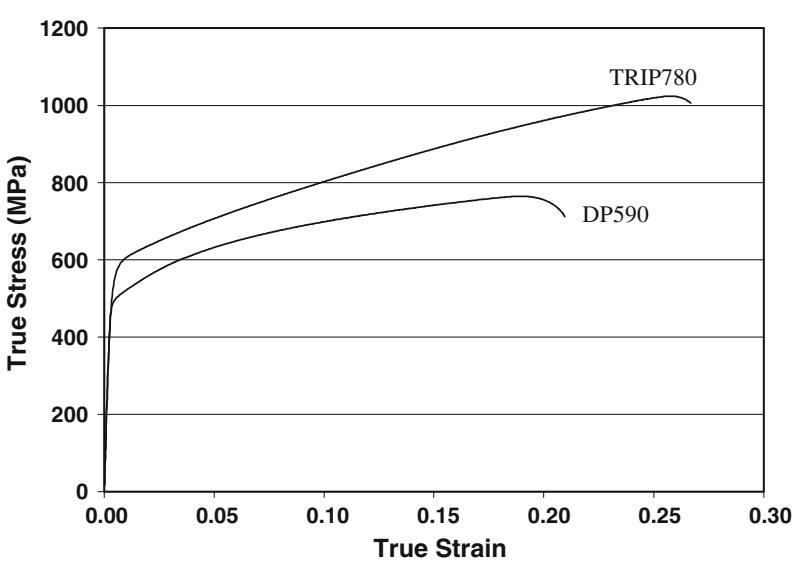

Fig. 3-True stress-strain tensile plots of the DP 590 and TRIP 780 steel.

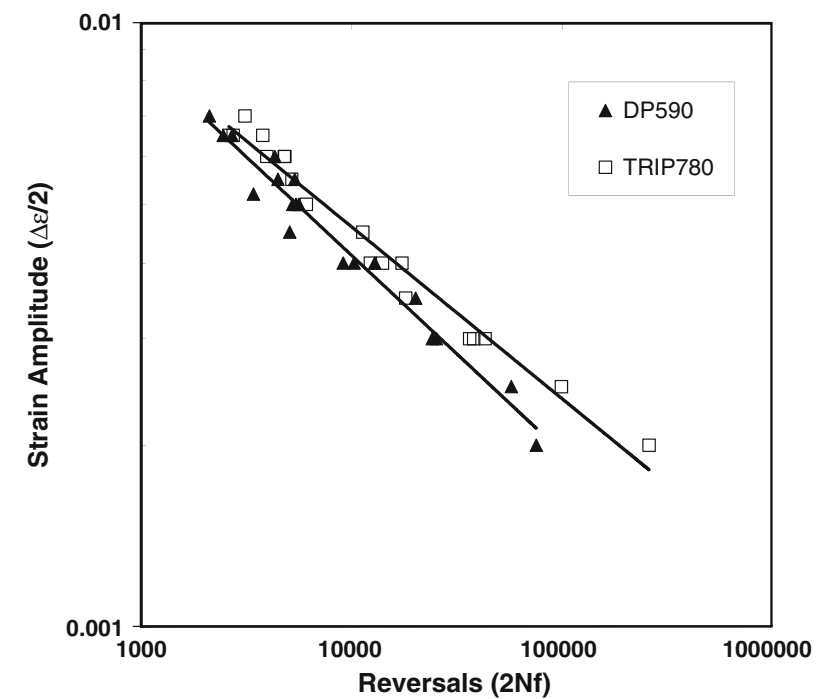

Fig. 4-Strain amplitude vs number of reversals-to-failure for the DP 590 and TRIP 780 steels.

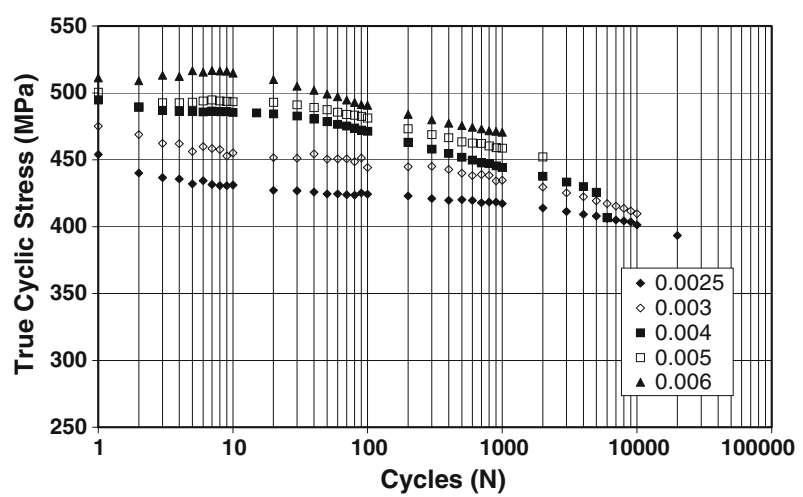

Fig. 5-Peak tensile stress $v s$ number of cycles plot for DP 590 for strain amplitudes ranging from 0.0025 to 0.006 .

constant cyclic softening occurred for the duration of the test until failure. At a strain amplitude of 0.006 , a small amount of cyclic hardening occurred during the 


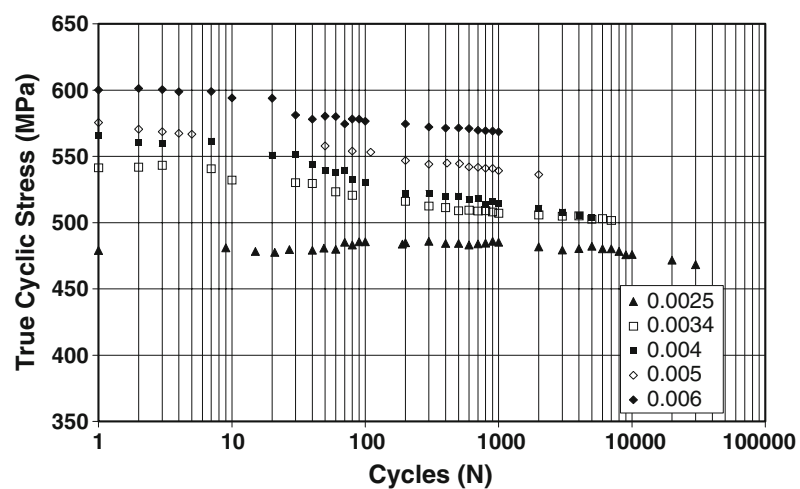

Fig. 6-Peak tensile stress vs number of cycles plot for TRIP 780 for strain amplitudes ranging from 0.0025 to 0.006 .

first 10 cycles followed by cyclic softening until failure. The amount of cyclic softening in the early cycles depended on the strain amplitude with an increase in softening occurring with a reduction in strain amplitude. At a higher number of cycles, the higher strain amplitudes appeared to cyclically soften at a faster rate than the lower strain amplitudes. The existence of a transition from cyclic softening at lower strain amplitudes to cyclic hardening at higher strain amplitudes during the first 10 cycles has previously been shown by Roven and $\mathrm{Nes}^{[14]}$ for low carbon ferritic steel. This transition was attributed to the change from cyclic softening due to the formation and spreading of dislocation sources at low strains, to ordinary work hardening obtained by rearrangements of the dislocation structure from walls and cells to subgrains and microbands and their subsequent refinement at higher plastic strains.

Cyclic softening also occurred for TRIP 780 for the majority of strain amplitudes tested, as shown in the peak stress $v s$ number of cycles plot in Figure 6. During the first 10 cycles, the cyclic stress remained relatively stabilized for strain amplitudes above 0.0025 , with cyclic softening dominating at higher cycles. At the strain amplitude of 0.0025 , the cyclic stress remained relatively stabilized until approximately 10,000 cycles before significant softening occurred. In contrast to DP590, no cyclic hardening occurred for TRIP 780 at strain amplitude of 0.006 .

The cyclic stabilized strength and first cycle tensile strength have been plotted against the strain amplitude in Figure 7 for both materials, with the cyclic stabilized strength being taken as the cyclic tensile stress at the half-life. This plot shows for DP 590 that the amount of cyclic softening depended on the strain amplitude, tending to decrease with increasing strain amplitude. The dependency of the amount of cyclic softening for the TRIP steel was similar to the DP steel at the higher strain amplitudes. However, at the lowest tested strain amplitudes there was a noticeable decrease in the amount of cyclic softening, suggesting a maximum in the cyclic softening at a low to intermediate strain amplitude. This maximum is highlighted in Figure 8 with cyclic softening plotted against strain amplitude, which shows that while both steels had similar softening levels in the strain amplitude range of 0.004 to 0.006 ,

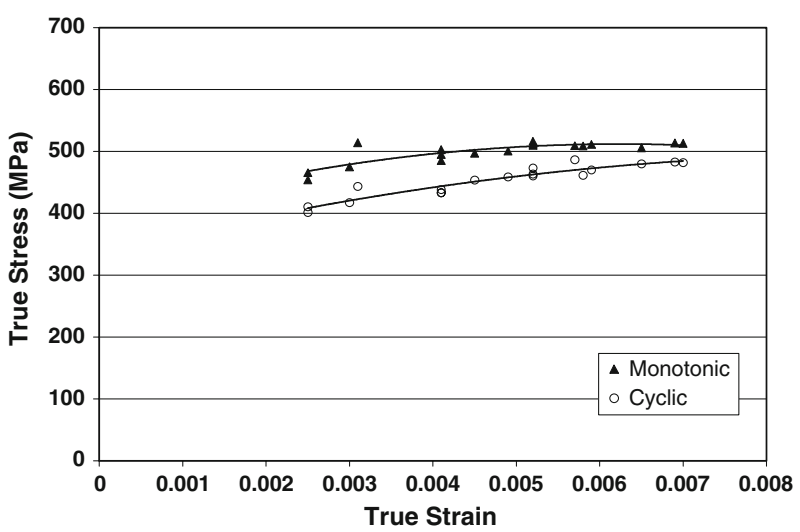

(a)

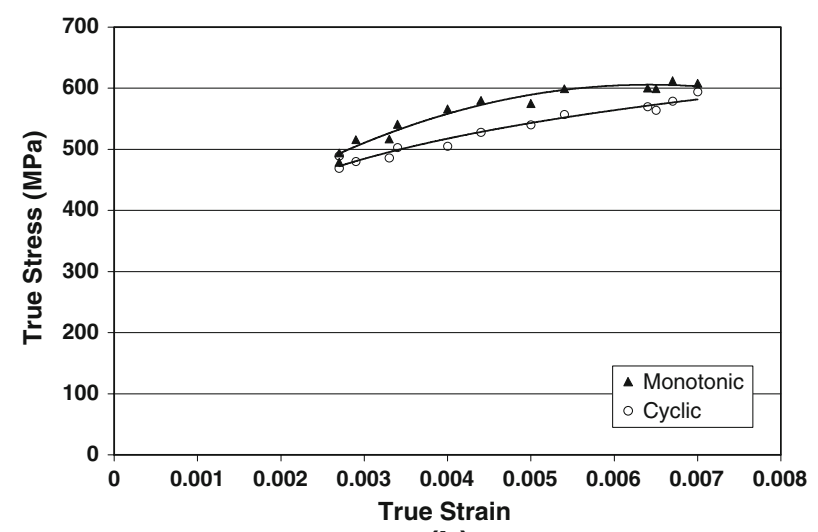

(b)

Fig. 7-Cyclic stabilized strength and first cycle tensile strength vs strain amplitude for (a) DP 590 and (b) TRIP 780.

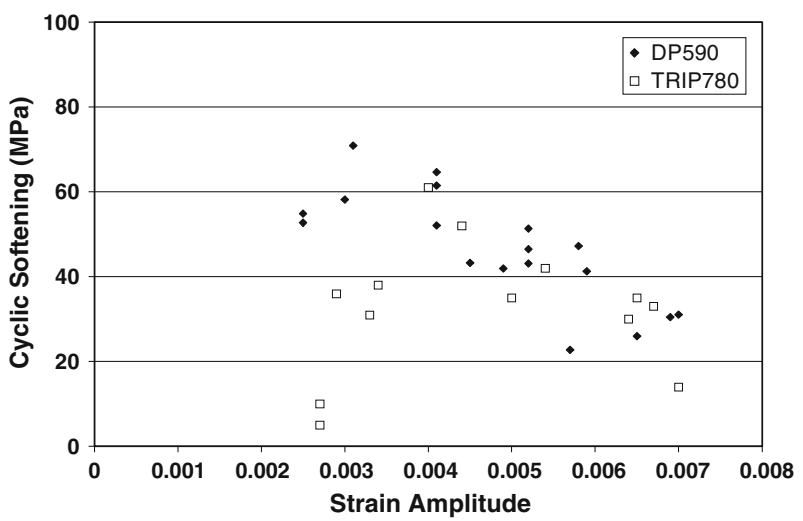

Fig. 8-Magnitude of cyclic softening vs strain amplitude for DP 590 and TRIP 780, with cyclic softening determined as the difference in stress between the initial cycle and the cyclic stabilized stress.

there was a divergence in behavior in the lower strain amplitude range. At strain amplitudes below 0.004, DP 590 softened noticeably more than TRIP 780. Since for a given strain amplitude there is a difference in reversalsto-failure for the two steels, the cyclic softening has also been plotted against number of reversals in Figure 9. This plot shows a cyclic softening maximum for both steels, though these peaks occur at a different number of 


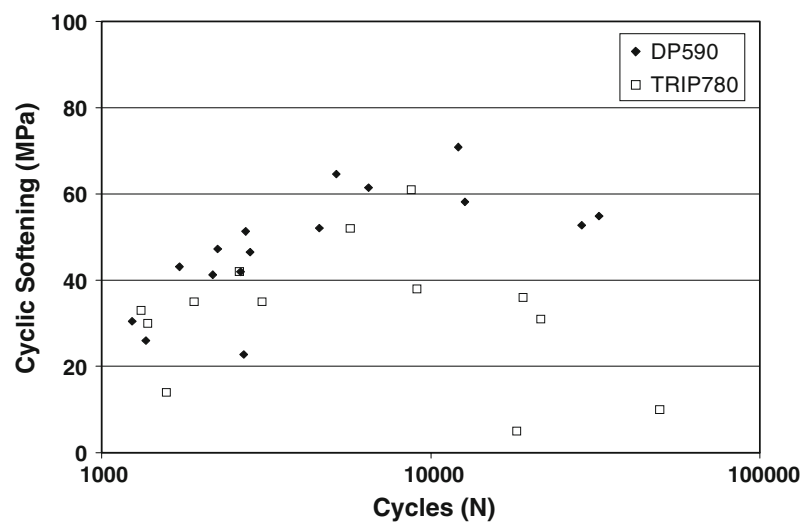

Fig. 9-Magnitude of cyclic softening vs number of cycles for DP 590 and TRIP 780, with cyclic softening determined as the difference in stress between the initial cycle and the cyclic stabilized stress. reversals-to-failure (although the order of magnitude of approximately 10,000 reversals-to-failure for this peak is similar for both steels).

\section{Microstructural Characterization after Fatigue Testing at Low-Strain Amplitude (0.0025)}

The DP microstructure showed wide dislocation structure variations in the ferrite from grain to grain after cyclic deformation at the lower strain amplitude (Figure 10(a)). In some ferritic grains, only a high density of homogeneously distributed dislocations was found (Figure 10(b)). Most of the grains, however, revealed the formation of a lower energy dislocation configuration cell structure, i.e., the standard micromechanism of recovery with the formation of a cell structure through dislocation rearrangement, when
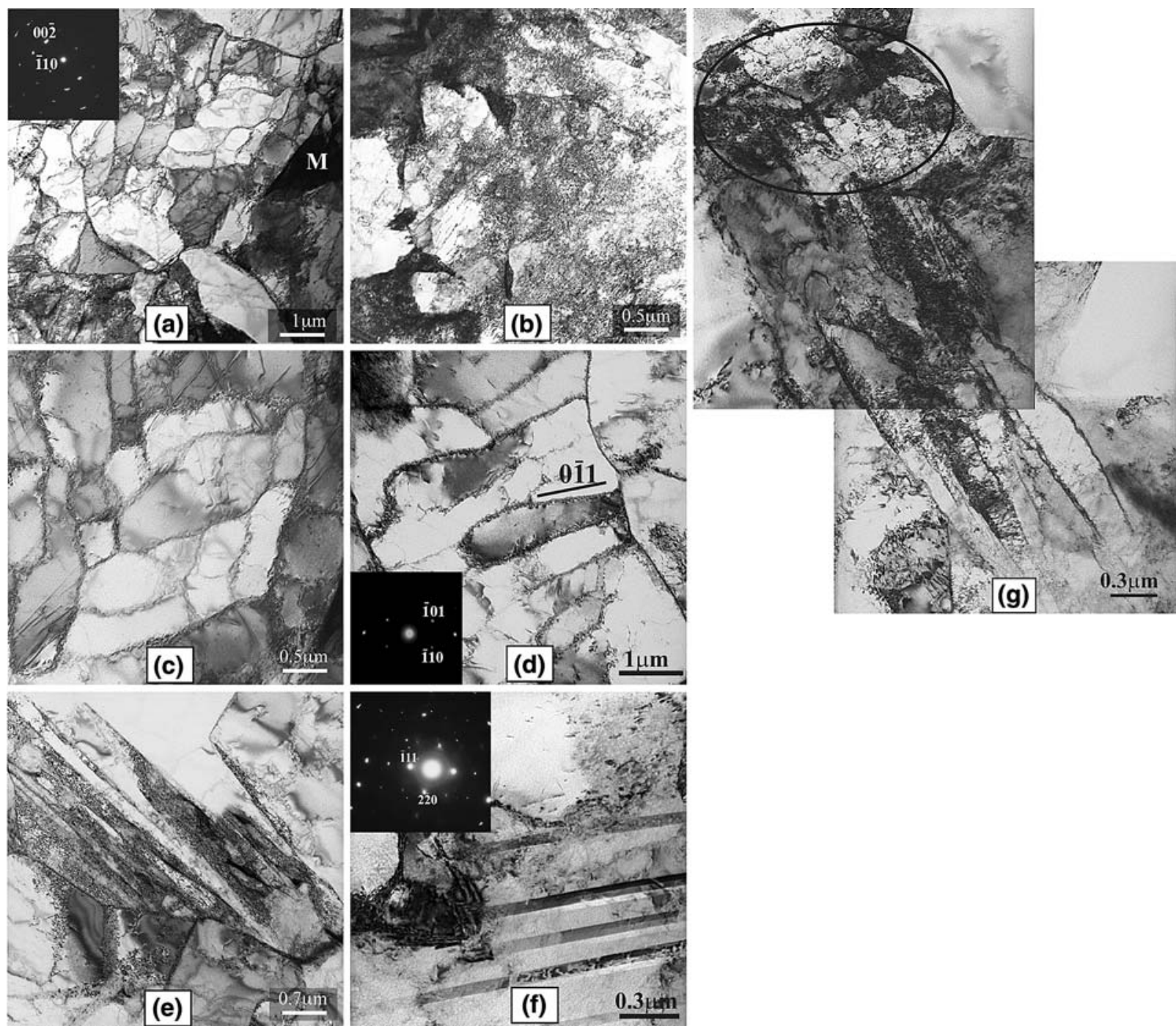

Fig. 10-TEM micrographs of DP steel microstructure after fatigue testing for 32,440 cycles at a strain amplitude of 0.0025 : (a) general view of cell structure (zone axis is $\left.[110]_{\alpha}\right) ;(b)$ grain with an increased dislocation density; $(c)$ cell structure formation; $(d)$ microbands and subgrains formation (zone axis is $\left.[111]_{\alpha}\right)$; (e) thin deformation bands, which ended in the middle of the grain; $(f)$ microtwins in austenite (zone axis is $[110],(\overline{1} 11),[\overline{11} 0])$; and $(g)$ stress concentration zone at the end of shear bands. 
tangled cell walls are transformed into more regular dislocation networks, reducing the number of dislocations in the cell interior (Figure 10(c)). ${ }^{[24]}$ The cells become clearly defined with relatively sharp cell boundaries, low angle of grain boundary misorientations, and an equiaxed shape with an average size of $0.6 \pm 0.2 \mu \mathrm{m}$ (Figure 10(c)). The formation of the dislocation cell structure in the ferrite appeared to be due to the two possible slip systems that can be active within one ferrite grain. The dislocations of these two systems can react and create a low-energy dislocation configuration. ${ }^{[15]}$

There were three types of deformation bands observed in the microstructure; parallel microbands, which did not cross grain boundaries (Figure 10(d)), thin deformation bands, which ended in the middle of the grain (Figure 10(e)), and shear band clusters (Figure 10(f)). The parallel microbands had an average thickness of $0.6 \pm 0.08 \mu \mathrm{m}$ (Figure $10(\mathrm{~d})$ ). The microbands also had sharp boundaries and low boundary misorientations ( 2 to $4 \mathrm{deg}$ ). It appeared that most of the microbands were formed along the $\{110\}\langle 111\rangle$ slip system. The presence of these bands do not lead to local stress zone formation, however, they can act as sites for crack nucleation. ${ }^{[14]}$ The gradual formation of subgrains by the development of boundaries across microbands was observed in several grains, i.e., the microbands were divided along their length by sub-boundaries (Figure 10(d)). These subgrains had an elongated shape and a low to middle level of misorientation ( $<15 \mathrm{deg}$ ). The thin deformation bands displayed thick dislocation walls and low-angle boundary misorientations. The shear band clusters had a similar thickness to the parallel microbands and were arrested at the grain boundary (Figure 10(f)). In this case, a strong stress concentration region with an increased dislocation density formed in the adjacent ferrite grain (Figure $10(\mathrm{~g}))$. The probability of crack formation is high in this case due to the higher stress concentration in a local area.

Some of the retained austenite crystals demonstrated twinning (Figure $10(\mathrm{~g})$ ), although there were no observable deformation twins in the martensite.

The TEM of the TRIP steel revealed that ferrite plastically deformed before bainite or austenite, with the formation of a high dislocation density in the ferrite grains (Figure 11(a)). However, the formation of a cell or subgrain structure was not observed after testing as it was for the DP steel. This lack of cell formation could be explained by the larger ferrite grain size of the DP steel, as in larger grains a larger plastic activity could be developed, ${ }^{[25]}$ or alternatively by the lower plastic strain component for a given strain amplitude in the TRIP steel due to a higher yield stress (this mechanism is discussed further in Section III-F-1). The retained austenite crystals did not show deformation twins (Figure 11(b)) and the volume fraction of retained austenite in the microstructure was similar to that observed in the as-received conditions. It appeared that some retained austenite crystals initiated the formation of dislocation walls (Figure 11(c)), due to the local stress concentration at the ferrite/austenite interface (Figure 11(c)). The formation of single subgrains with a middle level of misorientation $(<15 \mathrm{deg})$ was observed all over the sample (Figure 11(d)) and some grains formed thick dislocation walls in two perpendicular directions (Figure 11(e)).

\section{E. Microstructural Characterization after Fatigue Testing at High Strain Amplitude (0.006)}

At the larger strain amplitude the subgrain structure became the dominant feature in the DP steel (Figure 12). Moreover, the subgrain substructure showed refinement with increasing strain amplitude. The average subgrain size was $0.3 \pm 0.1 \mu \mathrm{m}$, approximately half that of the 0.0025 strain amplitude. The formation of the refined subgrains as a dominant structure may have caused the reduction in cyclic softening compared to the lower strain amplitudes, as the refined subgrains can contribute as a strengthening mechanism against mobile dislocation movement.

The TEM showed that the majority of grains in the TRIP steel at the larger strain amplitude could roughly be divided into the following types (Figure 13(a)): (1) grains with an increased dislocation density (Figure 13(a), grain A), (2) grains containing equiaxed cells (Figure 13(a), grain B), (3) grains with parallel microbands (Figure 13(a), grain C), and (4) grains containing microbands and subgrains (Figure 13(a), grain D).

The equiaxed cells had a low to middle level of boundary misorientations ( $<15 \mathrm{deg}$ ), an average size of $0.8 \pm 0.3 \mu \mathrm{m}$, and had a similar morphology to those observed in the DP steel (Figure 13(b)).

The microbands observed in a number of grains showed a low level of boundary misorientations (2 to $3 \mathrm{deg}$ ) and relatively sharp boundaries (Figure 13(c)). The average microband thickness was $0.6 \pm 0.06 \mu \mathrm{m}$. The interiors of the microbands were free of dislocations, while the walls contained dislocation tangles. The majority of grains also showed the formation of subgrains by the development of walls across the microbands (Figure 13(d)). These subgrains revealed a low to middle level of boundary misorientations $(<15 \mathrm{deg})$.

While the measurement of retained austenite via X-ray diffraction could not be undertaken on such a small area, it appeared via TEM analysis that only approximately 2 pct of the retained austenite transformed to martensite during cyclic straining at the higher strain amplitude.

\section{F. Role of Microstructure in Fatigue Behavior}

\section{Strain life}

There are several potential contributing factors to the enhanced strain life of TRIP 780 compared to DP590: higher ductility, higher yield and tensile strength, and the presence of significant levels of retained austenite in the microstructure. Higher ductility typically improves the fatigue resistance of steels under high amplitude/ LCF due to an increased capacity to accommodate the cumulative plastic strains, whereas high tensile strength typically improves the resistance of low amplitude/ high-cycle fatigue. In the present work, it is anticipated 


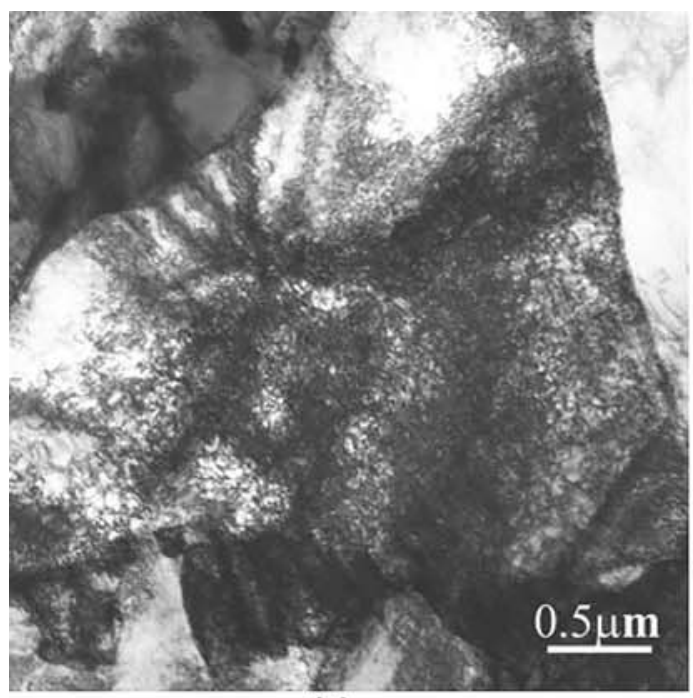

(a)

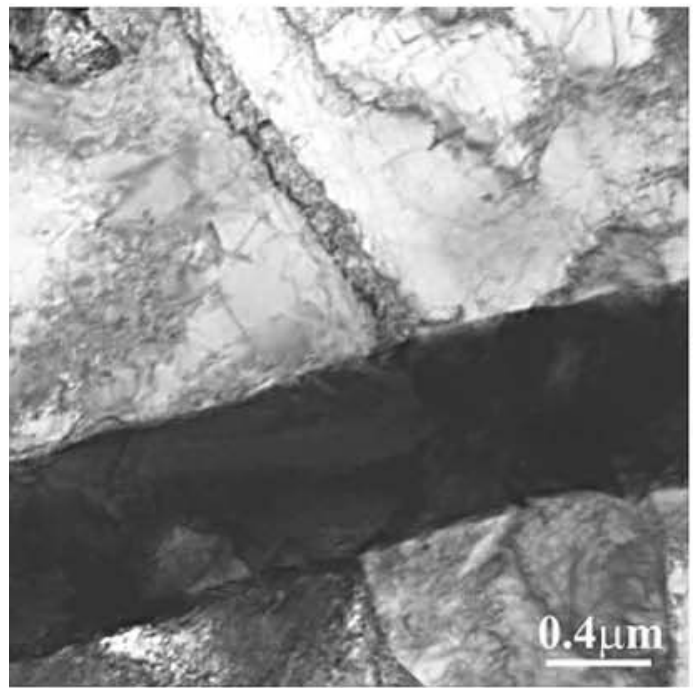

(c)

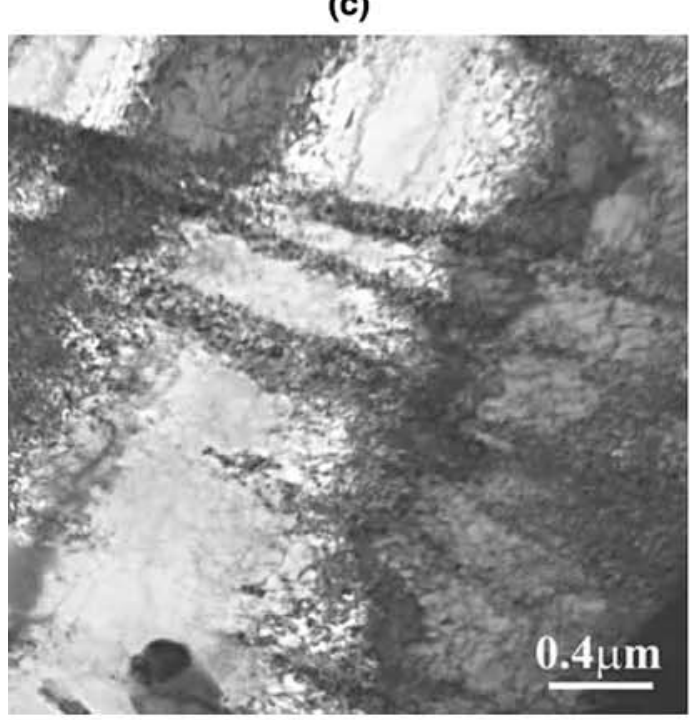

(e)

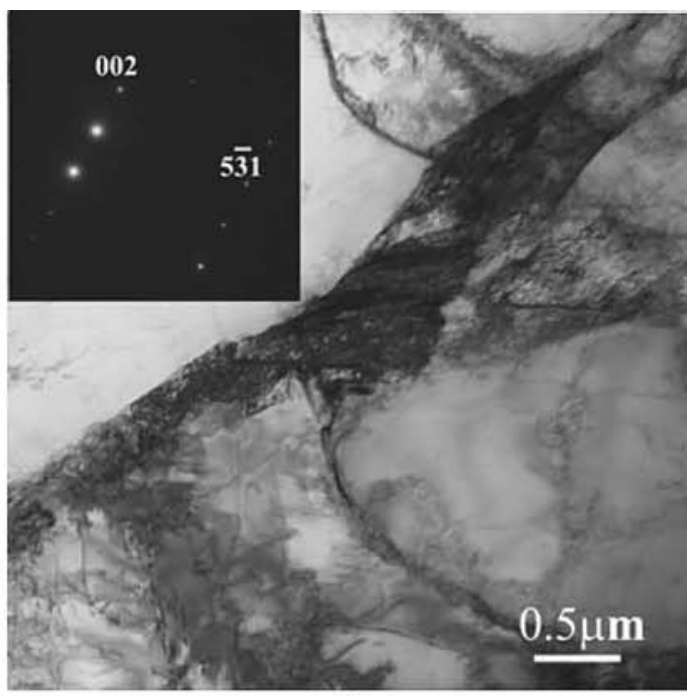

(b)

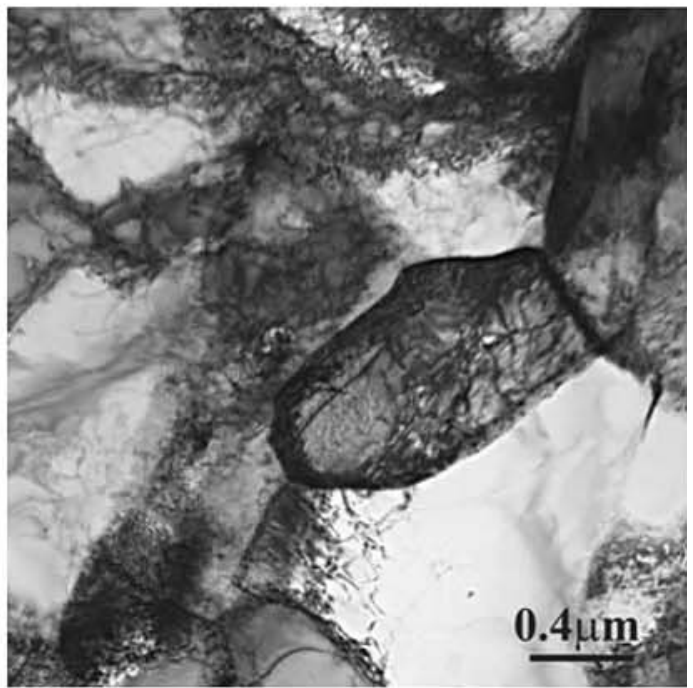

(d)

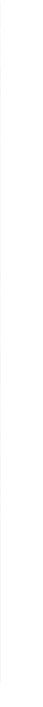

Fig. 11-TEM bright-field images of TRIP steel after fatigue testing for 49,582 cycles at a strain amplitude of 0.0025: (a) grain with increased dislocation density, $(b)$ retained austenite crystal (zone axis is [350]), $(c)$ formation of dislocation walls near the retained austenite crystal, $(d)$ formation of subgrain, and $(e)$ formation of two sets of perpendicular dislocation walls. 


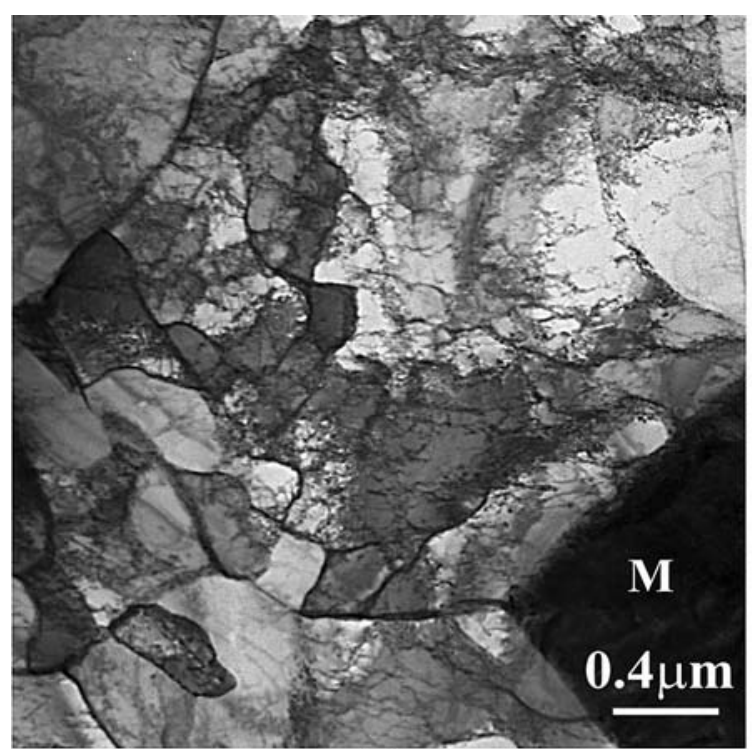

(a)

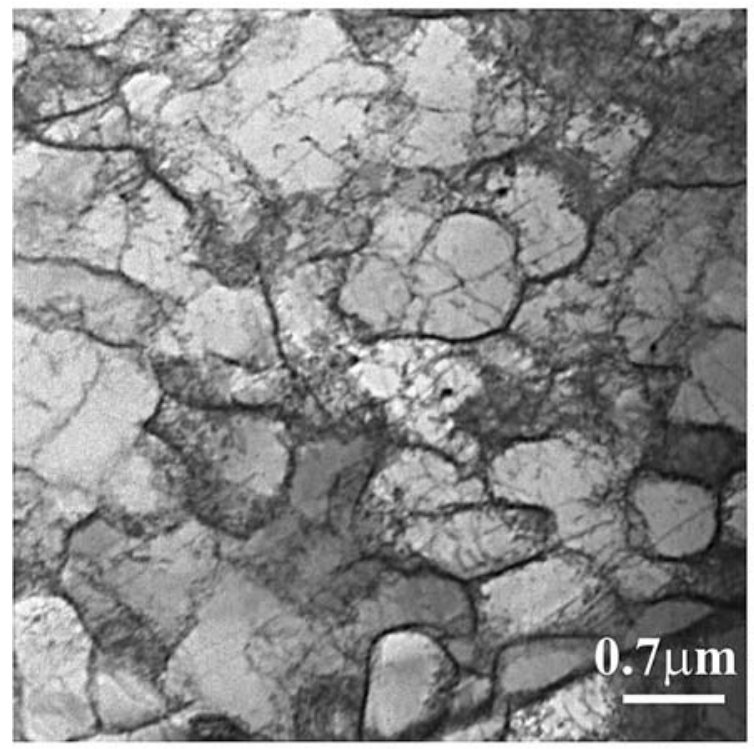

(c)

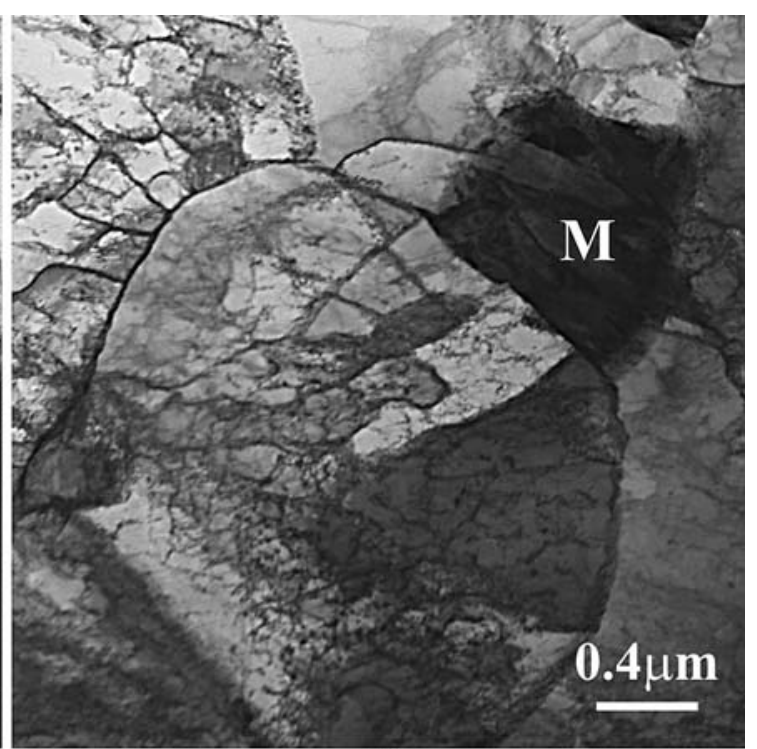

(b)

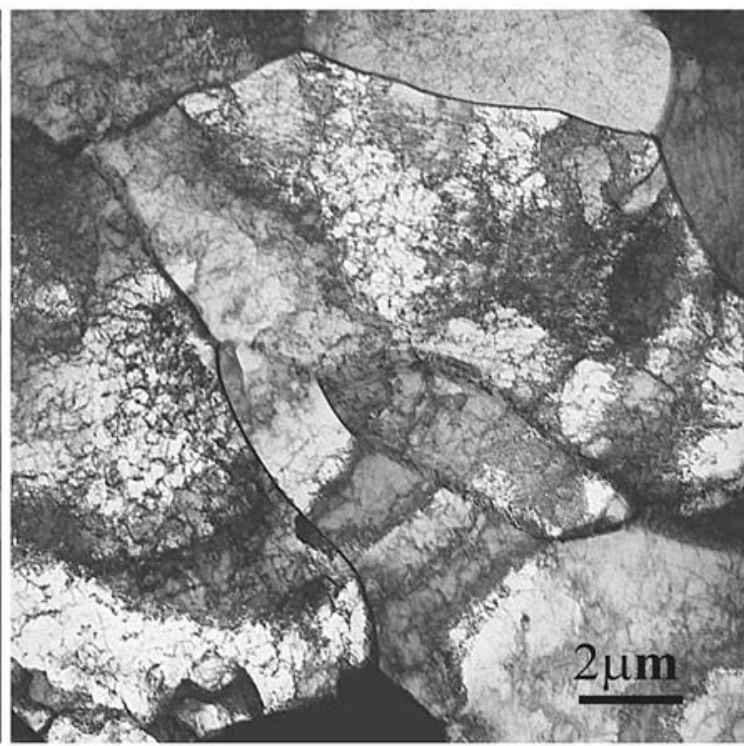

(d)

Fig. 12-Microstructural features formed in the DP steel after fatigue testing for 2173 cycles at a strain amplitude of 0.006 . M is martensite.

that both will contribute to the improved performance of the TRIP steel.

The importance of the increased yield strength is due to the greater component of elastic strain in each strain reversal for the TRIP steel compared to the DP steel, as the total strain amplitude for each reversal (sum of the elastic and plastic components) remained constant. Figure 14 shows that the elastic component of the TRIP steel is higher than that of the DP steel for a given number of reversals-to-failure. Since damage in a fatigue test is the result of accumulated plastic strain, the lower levels of plastic strain for the TRIP steel per reversal will result in less accumulated damage. Sherman and Davies examined dual-phase steels with differing martensite contents, and hence yield strengths under fully reversed cyclic straining. ${ }^{[12]}$ In that study, the fatigue life increased with increasing martensite content, hence strength, until approximately 30 pct martensite before decreasing with further martensite increase. This highlights the importance of ductility in fatigue life, as at the higher martensite volume fraction the strain life decreased with increasing yield strength due to a decrease in material ductility. This result shows that the effect of the higher elastic strain component is not necessarily dominant in prolonging fatigue life.

Previous research on the role of austenite in cyclic loading has also shown that there is an increase in strain life with higher levels of retained austenite, due to a delay in crack initiation and the retardation of crack propagation, ${ }^{[26]}$ both resulting from the strain-induced transformation of austenite to martensite. The TEM observations on the TRIP steel in the current study have 


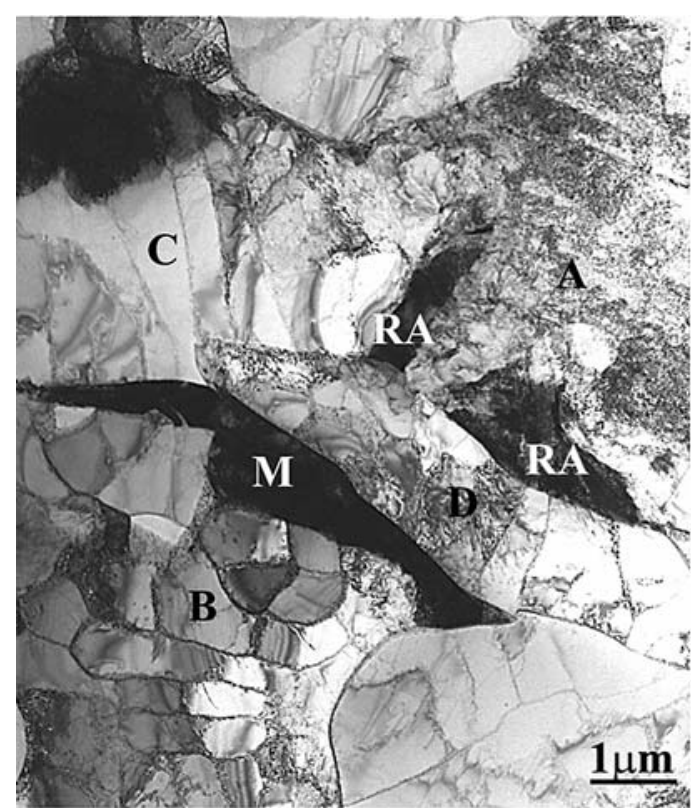

(a)

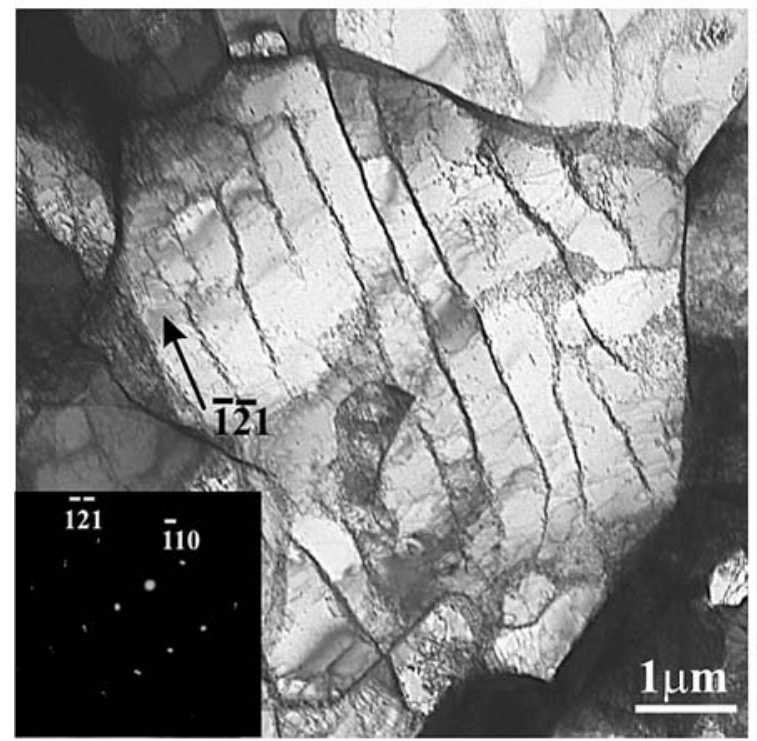

(c)

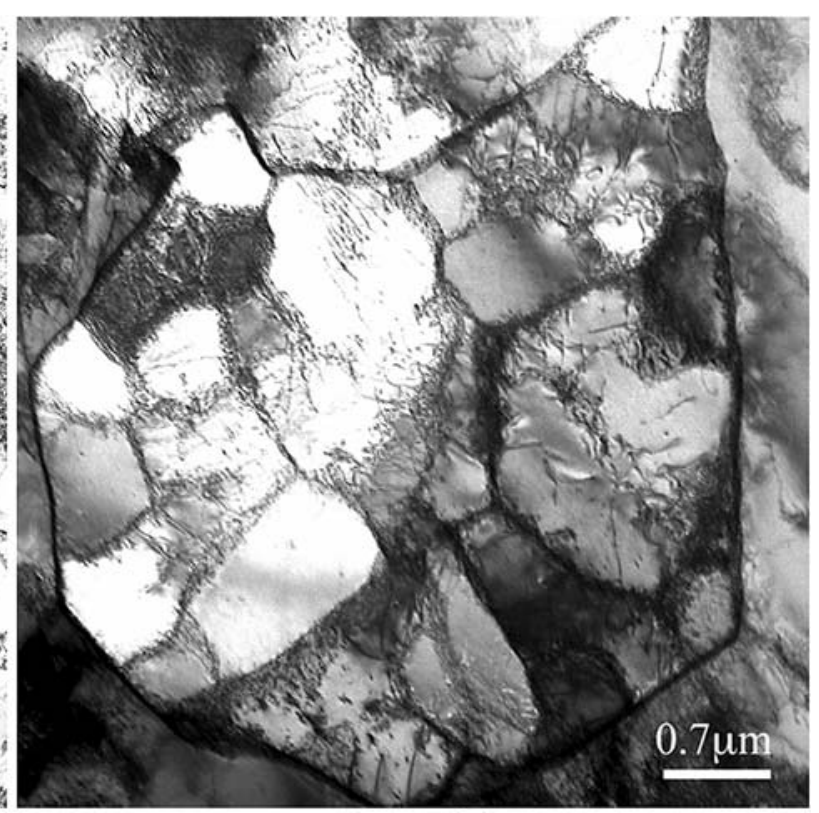

(b)

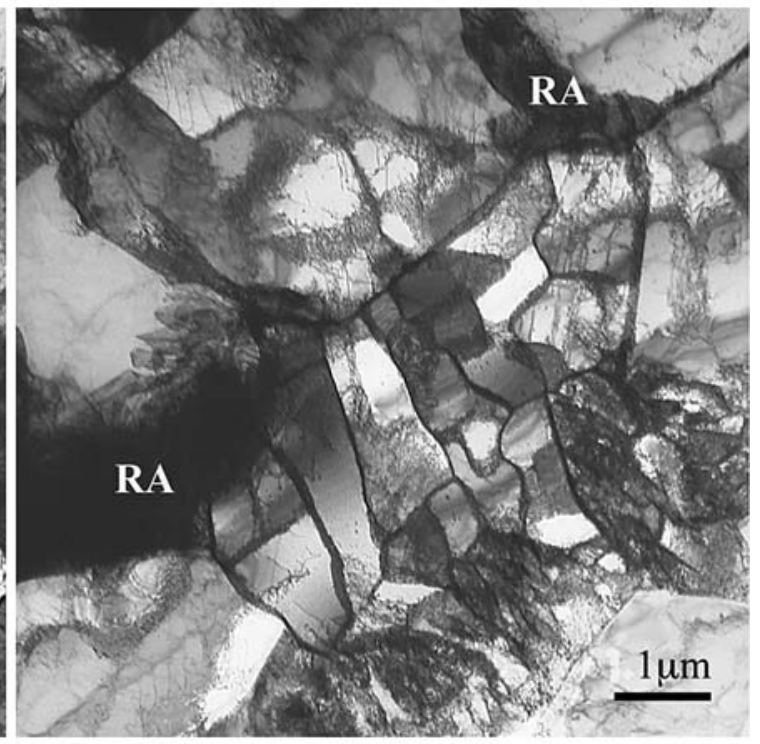

(d)

Fig. 13-TEM micrographs of TRIP steel after fatigue testing for 1379 cycles at a strain amplitude of 0.006 : $(a)$ general view, (b) formation of cell structure, $(c)$ formation of microbands (zone axis is [113] $]_{\alpha}$ ), and $(d)$ formation of subgrains. M is martensite and RA is retained austenite.

shown that there were not appreciable transformation levels of retained austenite to martensite in the deformed region of the fatigued specimens, however, the electron backscattering diffraction (EBSD) scan in Figure 15 shows that the austenite in the region surrounding the crack tip appears to have transformed to martensite. This transformation near to the crack tip suggests that some portion of the increased strain life for TRIP 780 compared to DP 590 may be due to crack retardation.

\section{Cyclic stress response}

Both the DP 590 and TRIP 780 cyclically softened at the range of strain amplitudes examined. This softening generated cyclic stress levels well below that of the as-received yield stress. Previous studies on dual-phase steels ${ }^{[12,13]}$ have predominantly shown cyclic hardening behavior over similar ranges of strain amplitudes to that used in this current study. Typical dual-phase steels, however, have a lower yield point to tensile strength ratio than the steel used in the currently study, resulting in significantly higher initial work-hardening rates. In general, materials such as DP steels with a high work-hardening rate will cyclically harden in the initial cycles due to the high numbers of dislocation generated in the initial strain cycle. Cyclic softening is primarily due to the generation of additional mobile dislocations, rearrangement of dislocation tangles developed during work hardening, and formation of a dislocation cell structure of lowered internal stress. The TEM revealed that both steels had a significant dislocation density in 


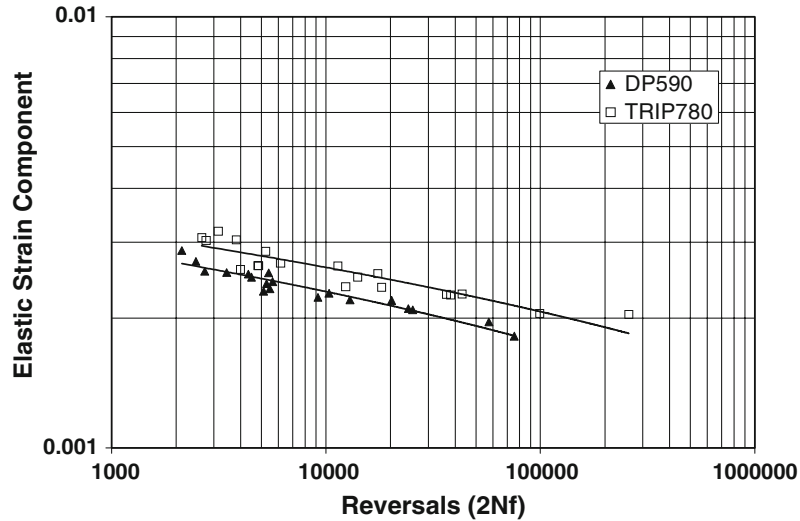

Fig. 14 -Elastic component of strain amplitude vs number of strain reversals for DP 590 and TRIP 780.

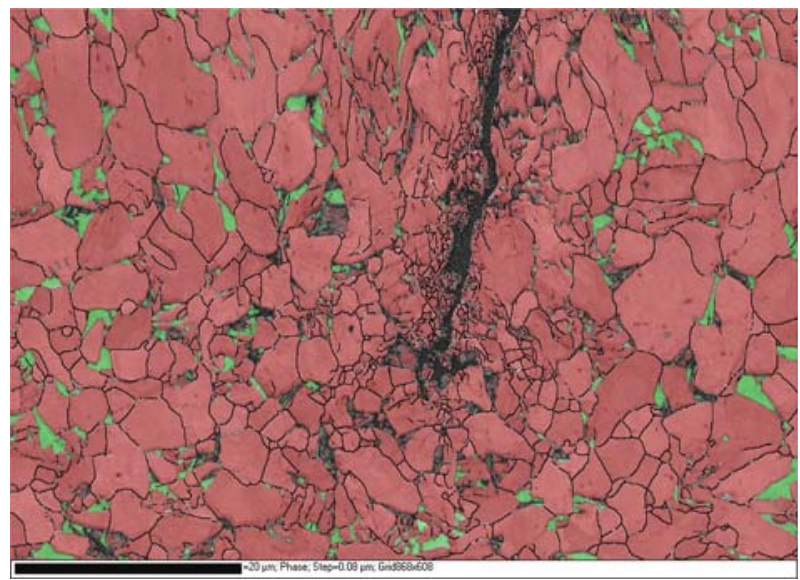

Fig. 15-SEM EBSD image of the crack tip in a TRIP 780 specimen showing regions of ferrite and martensite in red and retained austenite in green after fatigue testing for 49,582 cycles at a strain amplitude of 0.0025 .

the as-received ferrite grains, attributed to the compressive stresses caused by martensite formation during processing. The tensile behavior of both steels showed relatively high yield strength, suggesting there is significant dislocation pinning by carbon or nitrogen solute atoms. It is expected that the cyclic softening of both steels during cyclic deformation to levels well below the as-received yield stress is due to either the release of pinned dislocations, or alternatively the formation on new mobile dislocations in the ferrite. Kruml and Polak $^{[15]}$ have suggested that ferritic steels can cyclically soften within the first 10 cycles of low-strain fatigue due to the presence of dislocations of differing slip systems reacting to form low-energy configurations. These lowenergy configurations allow cyclic strain to be concentrated into bands of easy cyclic slip, resulting in significant cyclic softening. The TEM observations in this current study have shown that these dislocations exist within the DP 590 steel after fatigue.

The TRIP and DP steel used in this study had similar amounts of ferrite in the as-received condition, with the main microstructural difference being the substantial presence of austenite in the TRIP steel. Previous studies examining austenitic stainless steels subjected to cyclic straining have shown that this microstructure should have considerable hardening, ${ }^{[16]}$ resulting from the austenite to martensite transformation. The cyclic softening exhibited by the TRIP 780 in this current study suggests that there was very little transformation during cyclic straining, meaning that the fatigue behavior was essentially controlled by the ferrite in the microstructure. The low extent of austenite to martensite transformation in the bulk of the fatigue specimen was confirmed by TEM. Thus, for the two steels used in this study it appears that the similar levels of ferrite (approximately 70 to $75 \mathrm{pct}$ ) and low-strain work hardening have resulted in the similar cyclic response.

The TEM showed marked differences in the deformed microstructure between the two steels at the higher strain amplitude (0.006). The DP 590 had a relatively uniform well-refined dislocation cell substructure, whereas the ferrite grains in TRIP 780 contained a variety of different dislocation structures. The transformation of a small percentage of the austenite into martensite in the TRIP steel shows that some of the strain was accommodated by the austenite despite it being a harder phase than ferrite. Despite these differences between the two steels, the resultant amount of cyclic softening was similar at the higher strain amplitudes.

The main difference in cyclic softening behavior between the two steels was at low-strain amplitudes, where TRIP 780 exhibited very little cyclic softening. The TEM examination at this strain showed the development of a more defined substructure in DP590, including the formation of subgrains and parallel microbands, whereas in TRIP 780 these features were not present. Instead of showing the defined substructure, cyclic straining of the TRIP steel resulted in a higher density of dislocations within the ferrite than the as-received material. An explanation for this difference in fatigued microstructure can potentially be due to the proportionally higher elastic strain component at the 0.0025 strain amplitude for TRIP 780 (Figure 14). The low inelastic strain component for the TRIP steel may make it more difficult for dislocation rearrangement into lower energy configurations.

\section{CONCLUSIONS}

The strain life and cyclic stress response of two AHSS were investigated using fully-reversed strain-controlled LCF and the subsequent deformed microstructures characterized using TEM. The results showed that the following.

1. TRIP 780 showed an improved strain life compared to DP 590, which may be related to a combination of higher yield strength, higher ductility, and crack tip retardation by austenite to martensite transformation.

2. Both steels exhibited cyclic softening at the majority of strain amplitudes tested, which was due to the 
formation of lower energy dislocation substructures and parallel microbands. The similar levels of softening are believed to be due to similar ferrite volume fractions of the two steels, as well as similar low-strain work-hardening rates.

\section{ACKNOWLEDGMENTS}

The authors acknowledge the support of the ARC linkage and federation fellows programs.

\section{REFERENCES}

1. Y. Sakuma, O. Matsumura, and H. Takechi: Metall. Trans. A 1991, vol. 22A, pp. 489-98.

2. R.G. Davies: Metall. Trans. A, 1978, vol. 9A, pp. 41-52.

3. M.S. Rashid: in Formable HSLA and Dual-Phase Steels, A.T. Davenport, ed., TMS AIME, Warrendale, PA, 1979, vol. 244, pp. 1-24.

4. O. Matsumura, Y. Sakuma, and H. Takechi: Scripta Metall., 1987, vol. 21, pp. 1301-06.

5. G.R. Speich and V.A. Demarest: Metall. Trans. A, 1981, vol. 12A, pp. 1419-28.

6. W.W. Gerberich, P.L Hemmings, M.D. Merz, and V.F. Zackay: Trans. ASM, 1968, vol. 61, pp. 83447.

7. I. Tamura: Met. Sci., 1982, vol. 16, pp. 245-53.

8. V.F. Bhandarkar, V.F. Zackay, and E.R. Parker: Metall. Trans., 1972, vol. 3, pp. 2619-31.

9. J. Johansson and M. Oden: Metall. Trans. A, 2000, vol. 31A, pp. $1557-70$.

10. B. Yan and D. Urban: "Characterization of Fatigue and Crash Performance of New Generation High Strength Steels for
Automotive Applications (Phase I and Phase II)," AISI/DOE Technology Roadmap Program Report, AISI, Washington, DC, Jan. 2003.

11. T. Yokoi, M. Takahashi, and N. Ikenaga: SAE Technical Paper 2001-01-0042, SAE, Warrendale, PA, 2002.

12. A.M. Sherman and R.G. Davies: Int. J. Fatigue, 1981, Jan., pp. 36-40.

13. S.R. Mediratta, V. Ramaswamy, and P. Rama Rao: Int. J. Fatigue, 1985, Apr., pp. 101-06.

14. H.J. Roven and E. Nes: Acta Metall. Mater., 1991, vol. 39 (8), pp. 1719-33.

15. T. Kruml and J. Polak: Mater. Sci. Eng., 2001, vols. A319-A321, pp. $564-68$.

16. K. Basu, M. Das, D. Bhattacharjee, and P.C. Chakraborti: Mater. Sci. Technol., 2007, vol. 23 (11), pp. 1278-84.

17. K. Sugimoto, M. Kobayashi, S. Yasuki, and S. Hashimoto: Mater. Trans., JIM, 1995, vol. 36, pp. 632-38.

18. K. Sugimoto, M. Kobayashi, H. Matsushima, and S. Hashimoto: Trans. Jpn. Soc. Mech. Eng. A, 1995, vols. 61-581, pp. 80-86.

19. I.B. Timokhina, P.D. Hodgson, and E.V. Pereloma: Metall. Trans. A, 2004, vol. 35A, pp. 2331-41.

20. B.D. Cullity: Elements of $X$-Ray Diffraction, Addison-Wesley Publishing Company, Inc., London, 1978, pp. 411-15.

21. M. Onink, C.M. Brakman, F.D. Tichelaar, E.J. Mittemeijer, S. van der Zwaag, J.H. Root, and N.B. Konyer: Scripta Metall. Mater., 1993, vol. 29 (8), pp. 1011-16.

22. P.B. Hirsch, R.B. Nicholson, A. Howie, D.W. Pashley, and M.J. Whelan: Electron Microscopy of Thin Crystals, Butterworth and Co, London, 1965, pp. 51-54.

23. P.M. Kelly: Met. Forum, 1982, vol. 5 (1), pp. 13-23.

24. F.J. Humphreys and M. Hatherly: Recrystallization and Related Annealing Phenomena, Pergamon, Oxford, United Kingdom, 1996, p. 30 .

25. I. Alvarez-Armas, M.C. Marinelly, J.A. Malarria, S. Degallaix, and A.F. Armas: Int. J. Fatigue, 2007, vol. 29, pp. 758-64.

26. Z.Z. Hu, M.L. Ma, Y.Q. Liu, and J.H. Liu: Int. J. Fatigue, 1997, vol. 19 , pp. 641-46. 